\title{
Sentence Structure and Retention in Good and Poor Readers
}

\begin{abstract}
The purpose of the experiment was to discover whether syntactic structure facilitates recall in good readers, and whether, this effect exists in children who are poor readers. A paired-associate task equated the two groups on their ability to associate simple, familiar words. Each child was taught with a tape recorder, four lists, composed of nonsense elements, and grammatical markers; two of which, were syntactically structured, the other two, unstructured. The good readers learned the structured lists more rapidly than the unstructured lists. The poor readers learned both kinds of lists with equal difficulty. There was no difference between the good reader's and the poor reader's ability to retain the unstructured material. Hence, the locus of the facilitation effect lies in the syntactic cues, implicit in the structured list.
\end{abstract}

Rhona Weinstein

M.A. Thesis
Department of Psychology

August, 1968. 
WEINSTEIN - SENTENCE STRUCTURE AND RETENTION IN GOOD AND POOR READERS 
Sentence Structure and Retention in Good and Poor Readers

Rhona Weinstein

A thesis submitted to the Faculty of Graduate Studies and Research in partial fulfillment of the requirements for the degree of Master of Arts

Department of Psychology, MCGill University, Montreal.

August, 1968.

(C) Rhona Weinstein 1969 
Table of Contents

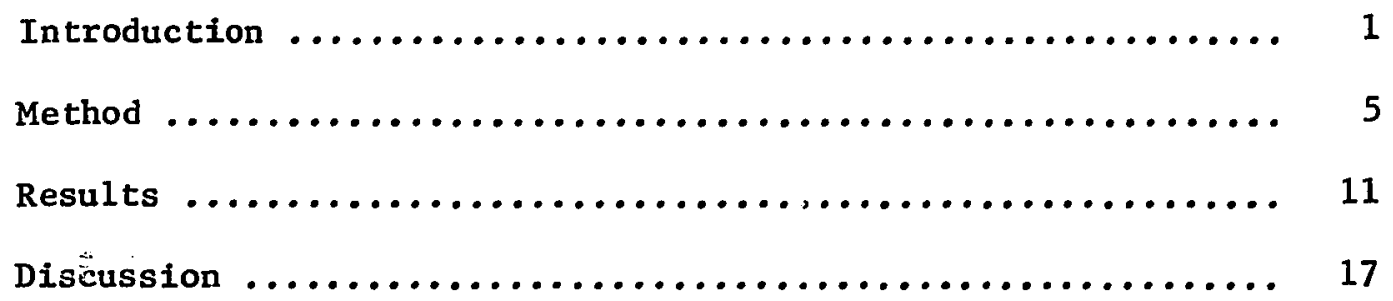


Some children of normal intelligence encounter multiple difficulties in learning to read and write. Bateman (1965) describes the child with special learning disabilities as one who manifests an educationally significant discrepancy between his apparent capacity for language behaviour and his actual level of language functioning. Such a child exhibits a constellation of correlated difficulties. An essential component of most learning disabilities, particularly reading retardation or dyslexia, is difficulty with sequential ordering. Orton (1937) has proposed that the interfering factor in the recognition or recall of a word is a failure to reconstruct the exact order of its constituent letters.

Lashley's (1951) discussion of the serial order phenomenon makes it clear that the individual items of a temporal series, for example, words, do not in themselves have an intrinsic valence. The order is imposed by far broader relations than the associative connections postulated by peripheral chain theorists. There must exist behind a sequence not only of language, but of all skilled movements, a complex of integrative processes. In the following sentence, proposed by Lashley (1951, p. 116) "The mil1wright on my right thinks it right that some conventional rite should symbolize the right of every man to write as he pleases", the arrangement of the elements cannot be due to the associations of "right" with the other words - the order must be determined by more extensive relations. The syntax of the sequence is that set of broader relations or rules. Lashley (1951, p. 122) suggests that "this is the essential problem of serial order; the existence of generalized schemata of action which determine the sequence of specific acts". 
The generalized schemata, in linguistic terins, are commonly referred to as grammatical markers (Fries, 1962), devices that signal the structural meaning of a word. Any word, in a complete utterance, when given a specific identifying marker, will be tagged as a member of one of four major formclasses (noun, verb, adjective and adverb). Any nonsense word can be tagged in the same way and will then take on the meaning of the particular part of speech. If the grammatical markers are omitted, structural ambiguities result. For example, the following utterance, "Ship sails today" could be interpreted as either "The ship sails today" or "Ship the sails today". In this case, the essential signals are lacking. Fries' (1962) classification of signals consist of 1 . the contrastive arrangement of form classes bound morphemes, 2. function words and 3. patterns of intonation. These signals must be known. One cannot, for example, use a nonsense word in the place of a function word: here, the signal of grammatical meaning in the following utterance "who is coming to dinner" lies in the word "who" alone.

Certainly, language presents a striking example of the integrative capacity of the human being. Serial organization is particularly iraportant in language learning. Grammatical markers serve as signals of structural meaning thereby imposing a predictable order on the recall of the elements composing the sentence. By investigating recall of a span of verbal material in children, one could determine how effectively or ineffectively these youngsters use the information available in the decoding of the grammatical markers. Epstein $(1961,1962)$ has reported that in adults, the recall of syntactically structured lists of nonsense syllables is superior to the recall of unstructured lists of nonsense syllables. The nature of the 1 ists can be 
described in terms of these components: (a) English function words, (b) nonsense syllable stems, and (c) English bound morphemes. The following is an example of Epstein's structured 1ists: A vapy koobs desaked the citar molently um glox nerfs. Epstein's experiment investigated three types of nonsense sentences. The structured list could be described as a grammatical "pseudo-English" sentence, since if its nonsense stems were replaced by English stems, a grammatical sentence would result. The unstructured list would contain the same items as the structured list, but in a scrambled order. It is unstructured in the sense that word order is ungrammatical. The third 1 ist was Identical to the structured list except that the bound morphemes had been deleted. Many English sentences do not contain bound morphemes, hence the sentence is not ungrammatical. However, the number of syntactic cues available to the reader or listener is reduced. Epstein (1961, 1962) found that structured 1 ists, with and without bound morphemes are learned in fewer trials than unstructured lists. Also, the addition of bound morphemes facilitates recall. The function words (e.g. the) and the bound morphemes (e.g. ed) serve as grammatical markers which associate a form-class to each nonsense stem. If a listener has perceived the syntactic structure of the list, he need not store information about the order in which the items appear. This information is explicit in the markers themselves. Recall may be related to the number of syntactic cues present in the 1ist. In Epstein's $(1961,1962)$ experiment, subjects were asked to recall the items in order. Forster (1966) proposed that the facilitation effect, apparent in the structured 1 ists, was due to the fact that the subject is not required to store information concerning item order. He tested the prediction 
that if subjects were not obligated to recall the items in order, the facilitation effect would disappear. He combined two variables in the construction of four lists; (1) whether the list was structured and (2) whether bound morphemes were present. A facilitation effect did appear; structured 1ists, with and without bound morphemes were recalled more efficiently than unstructured lists, under the conditions of non-ordered recall, however, here, the addition of bound morphemes was not a significant variable. The crucial variables then, in both these studies are the syntactic cues within the list, whether recall of the order of items is insisted upon or not.

The most efficient and effective way to reproduce the order of 1tems in a grammatically structured array, would be to utilize the markers, the syntactic cues. One would need to know (a) which marker was associated with what nonsense stem, and (b) what that particular marker implies about its place in the order of items. The present study attempted to investigate this process in children. It has been mentioned that dyslexics, particularly, have difficulty with tasks involving sequential ordering. The continuum of reading ability is an interesting and important variable to consider when one looks at the processes involved in learning structured and unstructured material.

The hunch was that both good and disabled readers would be able to associate words with the same facility. A paired-associate task was given to both the good and poor readers in order to test the two groups on their ability to associate words. However, it was anticipated that in the utilization of the grammatical markers, differences would most likely appear. 
The prediction was that poor readers would not respond to the syntactic cues and therefore would not be able to recall the serial order of the items any easier with the aid of markers than without them.

In order to test these hypotheses with children, it was necessary to generate a simpler set of lists than those used by Epstein $(1961,1962)$ and Forster (1966). Appropriate sentence frames were taken from children's readers and a new set of nonsense stems were generated using Forster's (1966) rules. A pilot study was done to determine the difficulty of the lists prepared, difficulty in terms of length or number of items to be learned. Previous experiments (Epstein, 1961, 1962; Forster, 1966) tested recall under the conditions of reading the material and written reproduction. Since poor readers are at a great disadvantage under such conditions, reading was eliminated from the experiment entirely. A tape recorder was used throughout the experiment, and the children were asked to learn the sentences by learning to repeat exactly what they heard.

Method

Subjects

Fourth-grade children, from three Montreal public schools were subjects in the experiment. They all spoke English as their native language and were all of approximately the same socio-economic level (middle ciass).

These children were given the Gates Reading Test (Gates, 1958). Reading ability level was determined by the average of the three subtests, speed and accuracy, vocabulary and comprehension. The control group of good readers, was selected from the upper third of the distribution of scores on the Gates Reading Test. Children, whose scores fell at the 50th percentile 
or lower defined approximately the lower third of the Grade 4 reading population and these children served as the experimental group of poor readers.

Since reading ability correlates with I.Q. scores (Mueh1 and Kremenak, 1.966), an effort was made to equate the two groups as closely as possible for I.Q. scores, as measured by the Henmon Nelson Tests of Mental Ability (Henmon and Nelson, 1958). The mean I.Q. for the control group was 112.46 with a range of 96 to 127, for the experimental group, 103.80, with a range of 95 to 116. These means were computed after 9 children were excluded from the data; in the control group, 6 children with an I.Q. over 127, and in the experimental group, 3 with an I.Q. under 95. Even with this precaution, the I.Q. difference between the experimental and control groups is statistically significant at the .001 level $(t=3.59)$. This necessitated the use of an analysis of covariance approach on all the statistics computed. Therefore two complete sets of statistics will be represented.

In a11, forty-one children were selected as subjects, twenty-six controls (good readers) and fifteen experimentals (poor readers). Ten children had been discarded at the outset of the testing session due to speech problems, emotional reactions to the material, and initial mechanical difficulties with the tape. Their results, of course, were never tabulated.

At the time of testing, the children ranged in age from 8.91 to 11.33 years. Mean age for the control group was 10.09, and for the experimental group, 10.04. This is not a reliable difference. Mean reading level for the control group was grade 5.70 and for the experimental group, grade 4.04 . This difference is significant at the .001 leve1 $(t=11.84)$. 
Preparation of 1ists

(a) Nonsense syllable stems: with the aid of a table of bigram frequencies in English (Underwood and Schulz, 1960), separate strings of 60 letters each, were prepared using a table for random numbers. Each string was cut into segments. The length of each segment was determined by English word-stems which were randomly selected from the Original Thorndike - Words 1 to 500 List (1944). The common words that children use comprise this 1ist. As an example, if the first four English word-stems had $6,4,3$ and 5 letters, respectively, then the string of bigrams was segmented after the $6 \mathrm{th}$, 10:h, 13th and 18th letters. This procedure generated potential nonsense-syllable stems. All syllables that were actual English words, were discarded, as were syllables that violated English orthographic rules, and were judged not pronounceable at the Grade 4 level. The stems used in the experiment were: (1) sivol, veg, hanash, zalf; (2) doo, swad, gozur, kaffal; (3) onuc, hend, tik, parf, imi; (4) rak, ibnu, lurm, wab, elir.

(b) Construction of lists: four English frames were selected from a Grade 3 reader. They were as follows:

(1) when they _ed the _, they _ed _ 1y.

(2) the _s _ed on the _quite _ly.

(3) _s _ed _as if _ ing to _.

(4) all the _ _

The structured 1 ists were constructed by inserting the stems in the available positions in the frames. Four unstructured lists were prepared by randomly rearranging the order of the items in each structured list.

Procedure

Under conditions of ordered recall, the children were asked to learn four sentences, two of which were structured, and two, unstructured. Four 
orders were prepared for the experiment and they are presented in Table 1. The first two frames were designated as type A since they were matched as to number of function words, number of bound morphemes, and number of stems. The third and fourth frames constitute type $B$ and were matched with aach other, according to the same criteria. Each child would learn one $A$ and one B frame in its structured form and the other $A$ and other $B$ frame in its unstructured form. Having four distinct orders (i.e. the material in each was different) made it possible for half of the 41 children to learn each sentence in its structured form, while the other half learned the same sentence in its unstructured form. The design also allowed an equal number of children to learn structured 1j.sts, followed by the unstructured lists, while the other half learned the unstructured lists first. The assignment of each child to one of the four orders, was determined by order of appearance. The orders were constructed so as to counteract the possible effects of (a) one list being equivalent in number of function words, number of bound morphemes, and number and length of nonsense stems, to another, yet learned more easily, and (b) of learning either structured or unstructured lists first, in terms of producing a set.

Each child was tested individually. A testing session lasted approximately one hour. If the child became tired or restless, testing was discontinued, either after the paired associate learning, or between lists, and continued within the following two days. Each order was recorded on tape by a male voice. The child listened to the material through earphones and was instructed verbally by the examiner that he would hear a funny sentence. He was asked to say aloud exactly what he heard, in exactly the 
Table 1

Content of the Four Orders

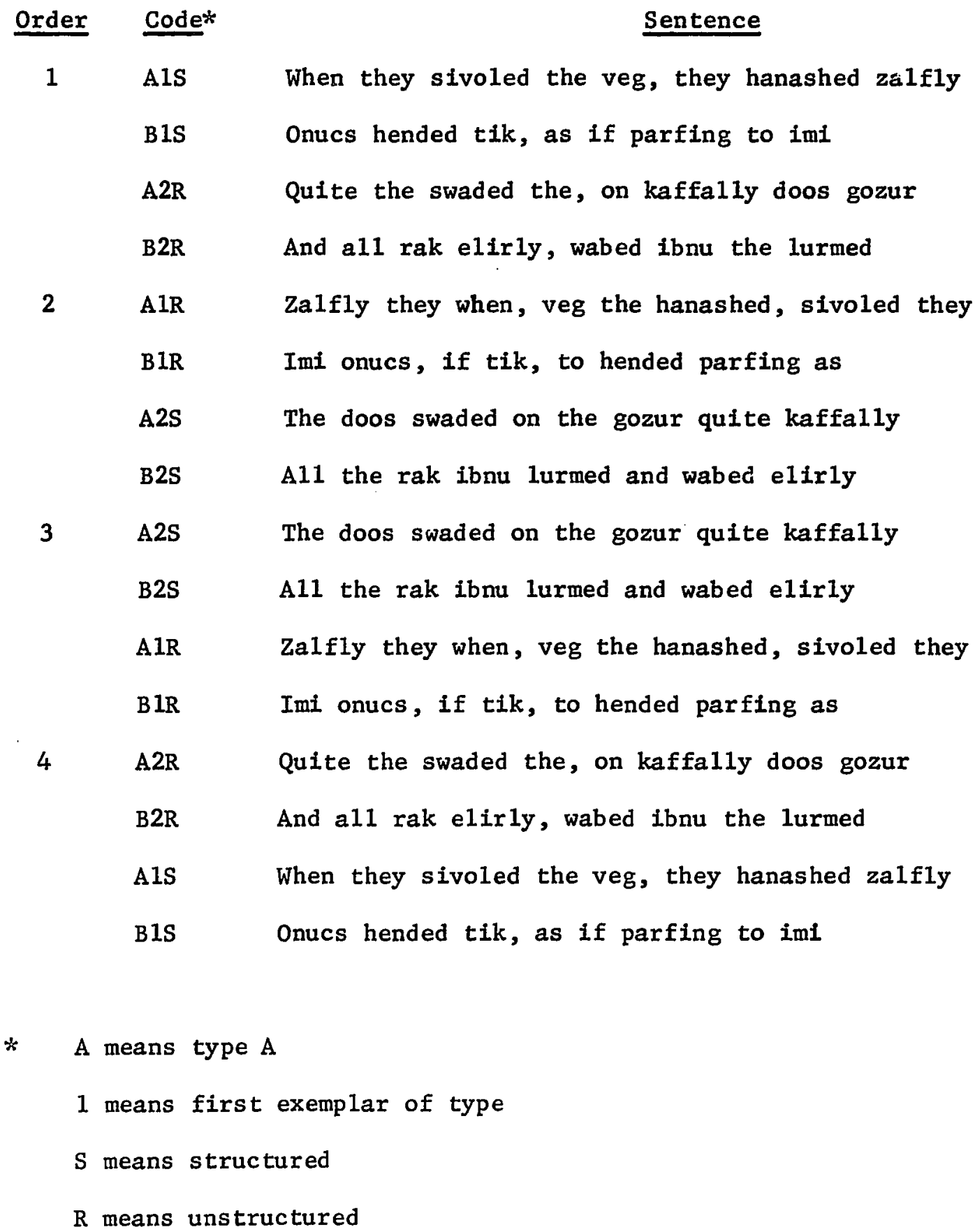


way he heard it. Immediately after the approximately 10 second learning perlod, the child was given as long as he needed to reproduce the list verbally. If incorrect, the material was presented again, followed by another test. This procedure was repeated until three reproductions, correct in terms of item order, were obtained. All four lists were learned by each child in this way.

Prior to the Iist-learning period of the experiment, each child, in both the experimental and control groups, was given a paired-associate task, containing six pairs of words. The words were chosen randomly from the Original Thorndike-Words 1-500 List (1944). The selection criteria were as follows, that each word contain four letters and that no two words of a pair begin with the same letter. The six pairs of words are presented in Table 2.

Table 2

Paired-Associates

$\begin{array}{lll}\text { food } & \text { - } & \text { soft } \\ \text { dark } & \text { - } & \text { pass } \\ \text { half } & \text { - } & \text { them } \\ \text { been } & - & \text { milk } \\ \text { cal1 } & \text { - } & \text { near } \\ \text { last } & \text { - } & \text { what }\end{array}$

The procedure was identical to that for the lists. The child listened through earphones to the recording of the pairs. The learning period took approximately 45 seconds and the interval between training and test, approximately 10 seconds. The child's verbal responses were checked - if incorrect all the pairs were replayed until the subject answered all the pairs correctly on three successive trials. 


\section{Resu1ts}

The mean number of trials required by each subject to reach the criterion of three correct verbal reproductions was computed for the pairedassociate task, the structured lists and the unstructured lists. Before this could be done for the nonsense material, it was essential to define empirically a correct reproduction. This was made difficult by the fact that the learning trials were in the auditory rather than the visual modality. Both the strangeness of the material, a combination of familiar with unfamiliar, and the human voice imperfections in the tape recording left room for a variety of minor misperceptions.

It was necessary to arrive at a set of workable rules that would define an acceptable response. The criteria that were held as most important were that the item order of the 1 ist must remain intact, and that all bound morpheme endings and function words must be pronounced correctly. If in any trial, either of these rules were violated, the trial was marked as incorrect. The child's verbal reproduction was further scanned - all of the children's less than perfect reproductions of the nonsense stems were analysed in three ways :

1) in terms of the frequency of occurrence of that approximation in good and poor readers.

2) In terms of the similarity of the given response to the correct response, for example, "ini" instead of "imi".

3) in terms of the frequency of mispronounciation of the initial consonant. Many children began the word "veg" with a letter other than "v", therefore, all the initial consonants used were considered acceptable. Whereas, in the case of "tik", only one child began the word with other than a " $t$ "; hence, that approximation was scored as an error. 
All approximated responses were empirically evaluated in this way until a table of acceptable approximations was generated to be used in scoring all the responses.

On the paired-associate task, the mean number of trials required to reach criterion was 14.23 for the control group and 17.00 for the experimental group. This is not a reliable difference $(t=1.25)$, suggesting that the good and poor readers can learn to associate simple familiar words with the same ease.

A comparison of trials to criterion for structured lists and unstructured lists in both the control group and the experimental group is represented in Table 3.

In the control group, structured lists were learned in fewer trials than unstructured lists $(t=7.67, p<.001)$. That is, the syntactic cues facilftated recall for the good readers. In the experimental group, the mean number of trials for structured lists was compared with the mean for unstructured lists; here, the difference is not significant $(t=1.72)$. The facilitative effect on retention associated with syntactic structure in good readers is not evident in the poor readers.

Only the presence of syntactic structure distinguishes the two kinds of material. A test for independent samples was done to determine the difference in ability as exhibited by both experimentals and controls for first, the structured lists, and then, the unstructured lists. The control group learned the structured lists more rapidly than the experimental group $(t=4.89, p<.001)$. In the case of the unstructured material, both groups learned the lists, with equal degree of difficulty. The difference here is not statistically significant $(t=1.53)$. 
Table 3

Mean Number of Trials to Criterion

Structured Lists Unstructured Lists

Controls

Mean

10.02

17.83

SD

6.28

5.06

Experimentals

Mean

17.00

19.97

SD

4.61

3.67 
Statistical Procedures to Control For the Effect of Intelligence

Though every effort was made to equate the good and poor readers on a measure of intelligence, the I.Q. scores of the control group were significantly higher than those of the experimental group. Since the HenmonNelson is a group intelligence test which requires the subject to read the items, and research findings have indicated the wide discrepancy in $I . Q$. points between group tests and individual tests administered to disabled readers, (Schiffman, 1962) it is highly probable that the good readers enjoyed a definite advantage. Nevertheless, it was decided to investigate the extent to which statistically significant differences in performance between good and poor readers could be attributable to differences in $I . Q$. test scores. An analysis.of covariance was computed to partial out the effects of intelligence on the following measures; 1) the Gates Reading Scores, 2) Difference scores - the score obtained for controls and for experimentals, when the mean trials to criterion for structured 1 ists is subtracted from the mean of the unstructured 1 ists, and 3) reading ability as a variable - controls and experimentals compared on structured materlal and unstructured material. The results are summarized in Tables 4 to 7 . The good and poor readers remain significantly differentiated as to their reading ability (Table 4). The difference score is a measure which essentially combines two earlier measures - a comparison of the effect of syntactic structure on the performance of both good and poor readers. Earlier, a correlated $t$ test was used for each group. Here, looking at the good readers, the discrepancy in performance on the two kinds of material is as a measure compared to the lesser discrepancy evident in the poor readers. 
Table 4

Analysis of Covariance to Remove Intelligence From the Gates

Reading Test Scores

\begin{tabular}{lccc}
\hline Sources of Variation & $\begin{array}{l}\text { Ad justed Sum } \\
\text { of Squares }\end{array}$ & d.f. & $\begin{array}{l}\text { Variance } \\
\text { Estimates }\end{array}$ \\
\hline Between Group & 16.19 & 1 & 16.19 \\
Within Group & 6.59 & 38 & .17 \\
Total & 22.78 & 39 & $\mathrm{~F}=93.35$ \\
& & $\mathrm{P}<.001$ \\
\hline
\end{tabular}

Table 5

Analysis of Covariance to Remove Intelligence

From Difference Scores

\begin{tabular}{lccc}
\hline Sources of Variation & $\begin{array}{l}\text { Adjusted Sum } \\
\text { of Square }\end{array}$ & d.f. & $\begin{array}{l}\text { Variance } \\
\text { Estimates }\end{array}$ \\
\hline Between Group & 241.48 & 1 & 241.48 \\
Within Group & $1,282.22$ & 38 & 33.74 \\
Total & $1,523.70$ & 39 & $\mathrm{~F}=7.16$ \\
& & $\mathrm{p}<.05$ \\
\hline
\end{tabular}


Table 6

Analysis of Covariance to Remove Intelligence

From Trials to Criterion on Structured Lists.

\begin{tabular}{lccc}
\hline Source of Variation & $\begin{array}{c}\text { Ad justed Sum } \\
\text { of Squares }\end{array}$ & d.f. & $\begin{array}{l}\text { Variance } \\
\text { Estimates }\end{array}$ \\
\hline Between Group & 358.81 & 1 & 358.81 \\
Within Group & 755.46 & 38 & 19.88 \\
Total & $1,114.27$ & 39 & $\mathrm{~F}=18.05$ \\
& & $\mathrm{P}<.001$ \\
\hline
\end{tabular}

Table 7

Analysis of Covariance to Remove Intelligence

From Trials to Criterion on Unstructured Lists

\begin{tabular}{lccc}
\hline Sources of Variation & $\begin{array}{c}\text { Adjusted Sum } \\
\text { of Squares }\end{array}$ & d.f. & $\begin{array}{c}\text { Variance } \\
\text { Estimates }\end{array}$ \\
\hline Between Group & .35 & 1 & .35 \\
Within Group & 564.25 & 38 & 14.85 \\
Total & 564.60 & 39 & $\mathrm{~F}=.02$ \\
& & $\mathrm{P}=\mathrm{N} . \mathrm{S}$. \\
\hline
\end{tabular}


With intelligence partialed out, the difference is significant at the .05 level (Table 5). Here again, the difference between a child's performance on structured material and unstructured material varies directly and rellably with his reading ability.

The difference between good and poor readers on the structured lists is again significant at the .001 level (Table 6), whereas performance on the unstructured lists, does not differentiate the good readers from the poor readers, as was found in the earlier statistics. The results of all comparisons were replicated in the analysis of covariance.

\section{Discussion}

The fact that the good and poor readers do equally well on the pairedassociate learning task is evidence suggesting that disabled readers can learn to associate simple familiar words with the ease of good readers. Research studies in the area of paired-associate learning with normal and retarded readers present contradictory findings. Otto (1961) found that good, average and poor readers - in that order, need increasingly more trials to learn a list of paired associates. His paradigm combined both visual and auditory presentation, for example, a picture of a diamond and the nonsense word "fep", thus complicating the association. Budoff and Quindland (1964) using auditory presentation of meaningful simple four letter words found that the disabled readers benefited more from this paradigm than the normal readers. In any case the control and experimental groups in the present study did equally well on a simple word association test.

The nonsense stems chosen for the lists were short, pronounceable and 
contained highly common letter combinations, e.g. "parf". It was assumed that both groups of children could associate these nonsense stems easily, with the markers that identify them - the function words and the bound morphemes - and with the stems that precede them and follow them. One could argue that because the test lists included both nonsense stems and familiar words, the paired-associate task could have dealt with nonsense words combined with the four letter monosyllables used. This was not done because of the danger of confusing the children in the subsequent learning of the lists. It is possible to include the nonsense elements in the pairedassociate paradigm by having two separate sessions for each subject.

Essentially, the assumption made on the basis of the data, is that both groups of children, upon tackling the structured and unstructured 1 ists were able to associate the nonsense stems with the grammatical markers. The difference between the two groups comes to light in the use they both make of syntactic cues. The data of the good readers is essentially a replication of Epstein's work with adults. The syntactic structure of the lists facilitates recall in the good readers but not in the poor readers. The fact that one cannot differentiate between good and poor readers on their ability to learn unstructured 1ists, but can with structured lists further substantiates the proposition that the locus of the effect lies within the syntactic cues. These results held up after the effect of the differences in I.Q. scores between the two groups, was removed.

If we use Braine's (1963) concept of "contexual generalization" to explain the acquisition of wosd order, then we require the mediating property of generalization to be extrinsic, namely temporal location in an utterance. 
There exist certain elements that recur in an infinite number of sentences these elements reduce the complexity of defining position. The child learns to recognize these markers and they begin to function as reference points. Braine proposes that "the positions immediately preceding or following such elements would then be defined in a fairly simple manner." (Braine, 1963, p. 329) Learning and generalization are assisted because words which appear in a given position are tagged by the marker specific to that position; tagged either by the function word or bound morpheme ending. The speculation is that poor readers have not generalized the grammatical markers. The good readers, through experience with, as an example, an "ed" ending in a particular location in many sentences, will be able to perceive the syntactic structure of the "ed" marker in a novel situation, where the stem to which it is attached is unfamiliar, that is, without meaning. The listener cannot rely on meaning to aid his retention of serial order. He must glean that information from the markers or begin to learn the list by rote association. It would appear that both good and poor readers approach the unstructured material with the latter method.

The need for a table of approximations added a somewhat cumbersome variable that could have been eliminated only by far better recording. However, since the interest here was item order, and intact markers, it was felt that the need to use a table of approximations was not an important factor.

An aspect of the data worth following through became evident in a partial analysis of the errors of 24 children, 14 of whom were good readers, and 7, poor readers. Many of the children exhibited a particular response 
which came to be called a perseveration response. It was defined as a response, not judged acceptable according to the empirical analysis of approximations, and one which appeared for a minimum of four successive trials. The perseveration response appeared in three ways: perseveration of the whole word, of segments of words (e.g. a bound morpheme ending), and of whole phrases.

Incidence of the perseveration errors was the first variable considered. Within the structured 1 ists, $29 \%$ of the good readers exhibited at least one perseveration response, compared to $86 \%$ of the poor readers. For unstructured material, the comparative percentages were $71 \%$ and $100 \%$. It is evident that disabled readers show a higher frequency of such errors, irregardless of the type of material, and also, that such errors are more apt to appear in unstructured material. This is further verified in the measure of incidence within a single list learning period. Within the structured lists, no good readers exhibited more than one perseveration response within a single 1 ist, whereas, $29 \%$ of the poor readers did. Within the unstructured 1 ists, the comparison was $21 \%$ to $86 \%$.

Intensity, that is, length of time, measured by trials, that the child persisted in the particular response, was another variable considered. Each perseveration error was assigned a percentage score, the number of trials the response was made (including those trials not in succession) divided by the number of trials to criterion for that sentence. The fact that the number of trials to criterion is part of the calculation cancels out the effect of the fewer learning trials of the control group. For the structured list, the range in intensity of perseveration responses was, for the good readers, 
$46 \%$ to $72 \%$ with a median of $59 \%$, and for the poor readers, $33 \%$ to $96 \%$ with a median of $74 \%$. Within the unstructured 1 ists, perseveration response intensity ranged from $19 \%$ to $96 \%$ in the good readers with a median of $54.50 \%$, and from $30 \%$ to $100 \%$ in the poor readers with a median of $59.83 \%$.

This is the roughest of analyses, and on oniy part of the sample, yet this particular experimental design and the specific questions asked did not allow for a more quantitative attack on the problem of perseveration responses. However, they do appear in the children's responses. It is evident that sheer number and intensity of perseveration responses is one factor related to the poor readers' failure to learn the structured lists with the ease exhibited by the good readers. Although, both groups do not differ significantly in their recall of unstructured material, the incidence of perseveration responses appears as a factor in the poor readers' performance - intensity, here, is not an important factor. One might postulate that a perseveration response iill be made when the listener cannot process the auditory input efficiently. The child attempts an approximation and persists in using the only response available to him. Because the response given is not changed for a minimum of four trials, one infers, that, for the child, input and reproduction are matched, that is, the child thinks his response is correct, therefore, he no longer attends to the auditory input.

The results of this study must be seen in light of recent research findings relating socioeconomic status and reading ability level. Eisenberg (1966, p. 7) presents a comparison of sixth-grade reading levels, by the following school systems; a large urban centre, named Metropolis, Suburbia, the private schools, and Commuter County, a centre of exurbanite white collar workers, including rural groups of poverty stricken Negroes. The results of this comparison are represented in Table 8. 
Table 8

Sixth-grade Reading Levels by School System

\begin{tabular}{|c|c|c|c|c|}
\hline School System & Test & $\begin{array}{l}\% \text { retarded } \\
>2 \text { years }\end{array}$ & $>1$ year & $\begin{array}{l}\% \text { advanced } \\
>2 \text { years }\end{array}$ \\
\hline Metropolis & Stan ford & 28 & 57 & 9 \\
\hline Commuter County & California & 15 & 35 & 8 \\
\hline Suburbia & Iowa & 3 & 19 & 34 \\
\hline Independent & Stanford & 0 & 1 & 82 \\
\hline
\end{tabular}

Both Metropolis, and Commuter County, containing families at the bottom of the economic strata, encounter the greacest incidence of reading retardation. These findings invite a comparison of the retarded readers of the poverty areas with the poor readers encountered in this study, here all of middle class status. Are the causal factors involved of a different nature in each group? Singer (1968) pushed the variable of socioeconomic status to its extreme and chose as his sample good and poor readers from a culturally deprived area in Verdun, Quebec. He carried out the identical experiment to that described in the present study. Singer's (1968) poor readers matched his good readers in I.Q. scores - a somewhat surprising fact, since one might expect the poor readers, to score lower, The mean I.Q. score of all his subjects was somewhat lower than the mean I.Q. of the children in the present study, 101.4 compared with 107.5. Paired-associate learning was found to be the same in both groups. Both the good and poor readers used the grammatical markers of the structured 1 ists - evident in that their recall of the structured lists was superior to that of unstructured lists. One might infer, from these results, that other factors, social and motivational, are operating to retard the performance of the poor readers. The culturally deprived poor readers may 
not have the same difficulties, in this case, with grammatical cues, that the poor readers of the present sample have.

Future research tends to reach out heavily in the direction of the correlated difficulties of the poor reader. Since he is not employing the grammatical cues to retain item order, upon hearing the material, what happens when he reads the material. Is this analogous to the phenomenon of "droppei" endings" that dyslexic children often exhibit? Under what circumstances can a disabled reader use grammatical markers to decode the meaning of an utterance? One must also look at perseveration responses under more quantifiable conditions and discover under what conditions they tend to occur. 


\section{References}

Bateman, B. "An educator's view of a diagnostic approach to learning disorders." in Learning Disorders, VI, (Ed.) J. Hellmuth, Seattle, Special Child Publications, 1965.

Braine, Martin. "On learning the grammatical order of words." Psychological Review. $1963,70(4), 323-348$.

Buddoff, M. and Quindland, D. "Reading progress as related to efficiency of visual and oral learning in the primary grades." J. of Educ. Psychol. $1964,55,247-252$.

Eisenberg, Leon. "The epidemiology of reading retardation and a program for preventive intervention." The Disabled Reader, (Ed.) John Money. Baltimore, The Johns Hopkins Press, 1966.

Epstein, William. "The influence of syntactic structure on learning." Amer. J. Psych, 1961, 74, 80-85.

Epstein, William. "A further study of the effect of syntactical structure on learning." Amer. J. Psychol. 1962, 75, 121-126.

Fries, C.C. Linguistics and Reading. New York. Ho1t, Rinehart and Winston, 1962.

Forster, Kenneth I. "The effect of syntactic structure on nonordered recall." J. Verb. Learn. Verb. Behav. 1966, 5(3), 292-297.

Gates, A.I. Gates Reading Survey. N.Y. Bureau of Publications, Teachers College, 1958.

Henmon, V.A.C. and Nelson, N.J. The Henmon-Nelson Tests of Mental Ability. Manual. Boston. Houghton-Mifflin Co., 1958. Lashley, K.S. "The problem of serial order in behaviour." Cerebral Mechanisms in Behaviour. The Hixon Symposium. (Ed.) Lloyd A. Jeffress. John Wiley 1951. Muehl, Siegmar, and Kremenak, Shirley. "Ability to match information within and between auditory and visual sense modalities and subsequent reading achievement." J. of Educ. Psycho1., 1966, 57(4), 230-238. 
Orton, S.T. Reading, Writing and Speech Problems in Children. New York. Norton, 1937.

Otto, W. "The acquisition and retention of paired associates by good and poor readers." J. of Educ. Psychol. 1961, 52, 241-248.

Schiffman, Gilbert. "Dyslexia as an educational phenomenon." in Reading Disability Progress and Research Needs in Dyslexia. (Ed.) John Money. Baltimore. The Johns Hopkins Press, 1962.

Singer, Murray. "The effects of socioeconomic factors in sentence structure retention in good and poor readers." Honours Thesis. McGill University, 1968.

Thorndike, Edward L., and Lorge, Irving. The Teacher's Word Book of 30,000 Words. Bureau of Publications, Teacher's College, Columbia University, New York, 1944.

Underwood, B.J., and Schulz, R.W. Meaningfulness and Verbal Learning. New York. J.B. Lippincott Co., 1960. 